\title{
EL CINE COMO MEDIO DE CONSTRUCCIÓN DE MEMORIA Y TERRITORIO EN MEDELLÍN UNA APROXIMACIÓN A PARTIR DEL CONCEPTO DE NARRACIÓN DE WALTER BENJAMIN ${ }^{1}$
}

\author{
THE CINEMA AS A MEANS OF CREATING MEMORY AND TERRITORY IN \\ MEDELLIN. AN APPROACH BASED ON THE WALTER BENJAMIN'S CONCEPT \\ OF NARRATION
}

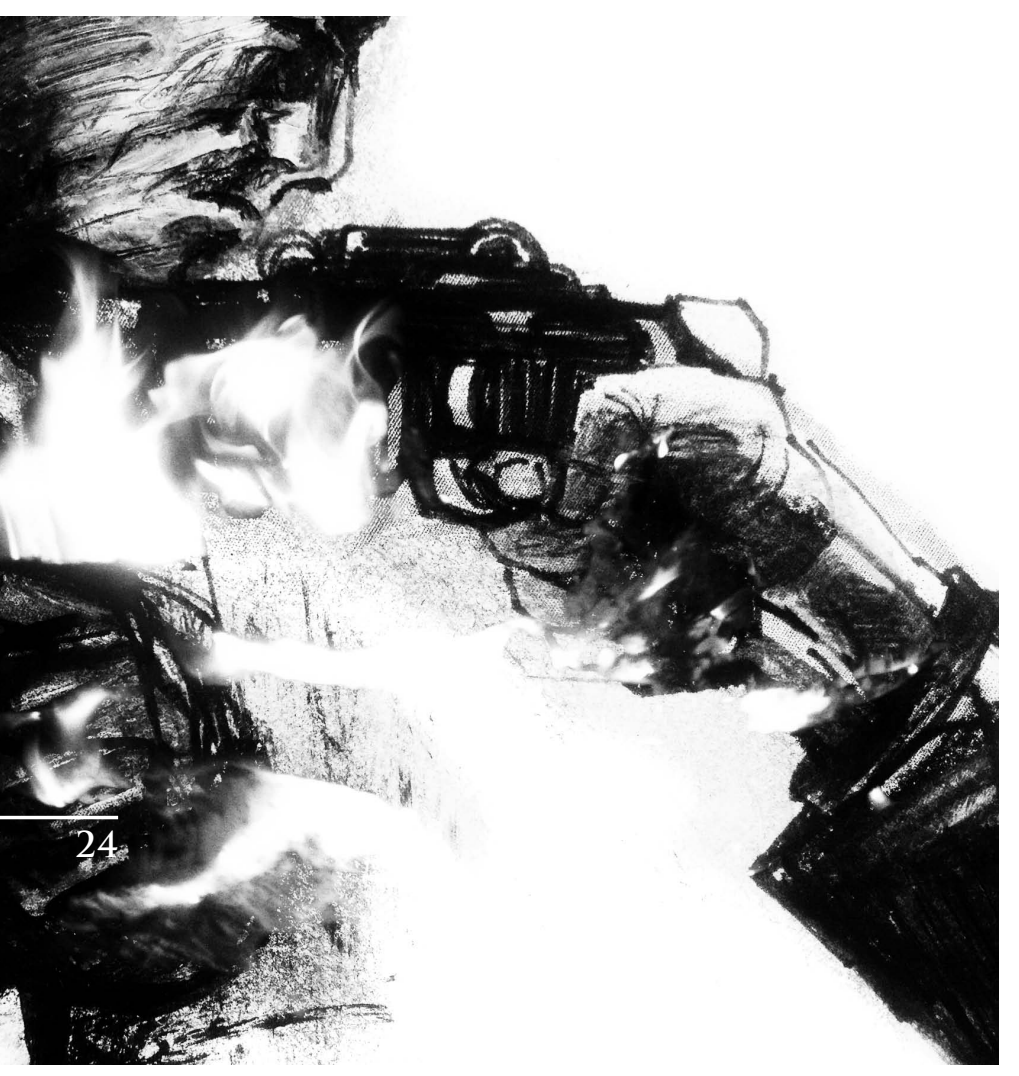

O CINEMA COMO MEIO DE CONSTRUÇÃO DE MEMÓRIA E TERRITÓRIO EM MEDELLIN. UMA APROXIMAÇÃO A PARTIR DO CONCEITO DE NARRAÇÃO DE WALTER BENJAMIN

Por:

Simón Puerta Domínguez ${ }^{2}$

Profesor

Universidad de Antioquia, Colombia simon.puerta@udea.edu.co

Resumen: Este artículo relaciona el concepto de narración de Walter Benjamin con algunas películas realizadas y tematizadas en la ciudad de Medellín, haciendo énfasis en las formas en que proporcionan un medio para la comunicabilidad de la experiencia y la visibilización de problemáticas y contradicciones sociales del contexto. El cine es un medio artístico que, por sus características técnicas, tiende hacia el narrar. Si bien este carácter narrativo no es inmanente a él, cuando es logrado permite la constitución de imágenes que responden a la complejidad de un contexto social determinado, que lo revelan. En el texto se argumenta que el cine realista que se ha elaborado en Medellín es un ejemplo de esto, particularmente en su afinidad con un uso de actores naturales.

Palabras clave: Medellín, narración, territorio, memoria, cine. 
Abstract: This article relates Walter Benjamin's concept of narration with some movies made and themed in Medellín city, emphasizing in the forms that provide a way for the communicability of experience and the visibilization of social problematics and contradictions of the context. Cinema is an artistic medium that, due to its technical characteristics, tends to narrate. Although this narrative characteristic is not inmanent to it, when it is accomplished, allows the constitution of images that respond to the complexity of a determined social context, that reveal it. In this paper it is argued that the realistic cinema that has been elaborated in Medellín is an example of this, particularly in its affinity with the use of natural actors.

Key words: Medellín, narration, territory, memory, cinema.

Resumo: Este artigo relaciona o conceito de narração de Walter Benjamin com alguns filmes realizados e que tem lugar na cidade de Medellín, fazendo ênfase nas formas nas quais proveem um meio para comunicar a experiência e a visibilização de problemas e contradições sociais do contexto. O cinema é um meio artístico que, pelas suas caraterísticas técnicas, tende à narração. Embora este caráter narrativo não é imanente ao cinema, quando isso é logrado permite a composição de imagens que refletem a complexidade de um contexto social determinado, que o revelam. No texto argumenta-se que o cinema realista que tem sido produzido em Medellín é um exemplo disso, particularmente na sua afinidade com o uso de atores não profissionais.

Palavras-chave: Medellin, narração, território, memória, cinema.

\section{Narración y experiencia}

El auge de la narración como aptitud de los hombres de comunicar su experiencia y la de otros corresponde a un momento histórico anterior al moderno, inversamente proporcional a la racionalización temporal y espacial, a los ritmos socialmente determinados de la eficiencia laboral que desde la emergencia del capitalismo como sistema integrador han avanzado hasta la actualidad, permeando todos los ámbitos de la sociabilidad humana. Uno de los grandes sacrificios del proceso de ilustración, muy articulado al detrimento general de la individualidad por la necesidad productiva de la estandarización o masificación de los bienes y los hombres en mercancías, es precisamente esta facultad, la de las relaciones entre individuos, para la experiencia y su transmisión, su apropiación colectiva.

En la figura del narrador, en su decadencia, Benjamin advierte que se está perdiendo, para su época (década del veinte), "la facultad de intercambiar experiencias" (1991, p.112), papel que le otorga a este actor histórico, y que va desde la importante transmisión oral hasta la recopilación en la escritura de un discurso colectivo, del cual hay, en su apropiación, también una participación. Hay una dialéctica entre 
memoria y olvido que, particularmente en la transmisión oral, pero también de los grandes escritores - los cronistas, desde Heródoto a Nicolai Lesskow-, los narradores despliegan al cumplir con dos habilidades fundamentales: saber narrar y saber no apartarse de los numerosos narradores anónimos, al tomarlos como fuentes (Benjamin, 1991, p. 112).

Que el arte de narrar se aproxima a su fin es un proceso que "viene de muy atrás" (1991, p. 115), y su manifestación de decadencia más temprana es el auge de la novela, a comienzos de la época moderna. Si la narración parte de una forma tradicional oral, situada en el ámbito de lo épico, la novela se determina en el libro escrito. En la narración, el que narra parte de la experiencia colectiva, en relación con su experiencia personal ${ }^{1}$, es decir, en él confluyen, como narrador, la experiencia propia y la transmitida, mientras que el novelista "se ha segregado", es el individuo en su soledad, aislado, tal como es tendencia general de la época burguesa, "desasistido de consejo e imposibilitado de darlo” (1991, p. 115). El que narra, por el contrario, tiene consejos para el que escucha. Por lo tanto, nos encontramos actualmente "desasistidos de consejo". Que el "«saber consejo» nos suene pasado de moda, eso se debe a la circunstancia de una menguante comunicabilidad de la experiencia” (1991, p.114)). A diferencia de una consideración moderna en la novela de la memoria como "memoria eternizadora", la memoria transitoria de la narración no se reduce a la generación de un relato con continuidad lógica, sin baches, sino que más bien, como en la epopeya, sería lo correspondiente a "muchos acontecimientos dispersos". Benjamin reúne ambas concepciones, de la novela y la narración, en una "unidad originaria del recuerdo" (1991, p. 125), que se escinde con el desmoronamiento de la epopeya. Si la narración, ahora escasa, se reconocía por su calidad de dar consejo, de ofrecer una moraleja de la historia, la novela, más ambiciosa, se vuelve tendencia en la modernidad como medio para encontrar un «sentido de la vida»; ambas son "posiciones históricas radicalmente diferentes" (1991, p. 126), y el carácter cerrado de la novela deja de ser complementario para ser un opuesto adialéctico con respecto al carácter abierto de la narración.

El desplazamiento de la narración como medio de comunicabilidad de la experiencia es el de una lógica mucho mayor de temporalidad y relacionamiento entre los hombres. En el estrepitoso ritmo de la sociedad de la competencia, la memoria pierde el espacio de su reflexión y reconfiguración permanente. Ella era fundamental para la reproducción -y transfiguración, cada vez- de lo narrado, al ser "la facultad épica que está por encima de todas las otras" (Benjamin, 1991, p. 124). Lo que deja ver este desequilibrio es, en términos más amplios para la consideración de la industria cultural, que la forma de comunicación ha ido cambiando de la épica, que mezclaba tanto la forma de la narración como de la novela, a la información, que es tan ajena a una como a otra. La información es, en la modernidad capitalista, determinante: en su forma como prensa, diario, dominical, etc., es "uno de los principales instrumentos del capitalismo avanzado" (Benjamin, 1991, p.116). La información se corresponde con su época, ella se constituye a partir de los ritmos de acero, y hace de la comunicabilidad un instrumento irreconciliable con una experiencia que no 
se reduzca a su abstractividad. La información "reivindica una pronta verificabilidad" (1991, p. 116), por lo que deja de ser importante lo lejano espacial o temporal.

Como es "imprescindible que la información suene plausible", es "irreconciliable con la narración" (1991, p. 117); se enfatiza en lo presente como instante o centelleo, en la fugacidad de la vivencia, opuesta al aburrimiento [Langeweile], el rato-largo que era el ámbito en que la experiencia colectiva se hacía memoria para el narrador (1991, p. 118). La memoria ya no relaciona pasado, presente y futuro, sino que enfatiza en el instante, como carácter práctico para las relaciones sociales mercantilizadas. La experiencia humana adquiere una valorización normativa, determinada por la relación o no, el interés o desinterés, con respecto a la lógica del sistema social; incluso la comunicación necesita hacerse valer como productiva.

\section{Cine y narración}

La narración estaba relacionada con una forma de comunicación oral que ha caído en desuso, tal como presenté, y que trascendía el ámbito mismo del narrar para remitirse a una dinámica social más profunda respecto a la memoria y su valor colectivo. En la misma época de su detrimento total, la época de masas, surge al mismo tiempo una nueva forma de comunicación que, como argumentaré, considero que actualiza la narración, le propicia una nueva forma, acorde a las dinámicas contemporáneas; me refiero concretamente al lenguaje cinematográfico. El concepto de narración de Benjamin no es, como podría pensarse, un romanticismo o un añorar un pasado supuestamente mejor. Lo que busca el berlinés es, más bien, recuperar elementos que hacen parte del ser humano mismo, de su creatividad y su posibilidad de apropiación del mundo, que con el avance impositivo de la razón instrumental en la modernidad capitalista ${ }^{2}$ se han ido opacando. No hay un llamado a la vuelta a la narración, tal como había existido históricamente, como identifica Benjamin, sino su necesidad de revitalización y potenciación en los lenguajes posibles por esa misma modernidad; de ahí que el cine no se vea más que como producto de su época, y su forma de narración, también.

La técnica que hace posible al cine también posibilita nuevos desenmarañamientos de la dimensión inconsciente de la sociedad. En otras palabras, como desarrolla Siegfried Kracauer (1995), "las películas parecen cumplir la misión innata de escarbar en la minucia” (p. 15). En su Teoría del Cine, de 1960, Kracauer desarrollará a cabalidad este argumento, señalando que hay "configuraciones efímeras, que sólo la cámara es capaz de captar" (1996, p. 40); el cine "tiene una franca afinidad con la realidad no escenificada" (1996, p. 40), que le permite captar lo particular: lo fortuito, lo fragmentario, lo indeterminado. La sociedad, la naturaleza y el individuo se presentan a la percepción ampliadas y profundizadas, a partir de la mediación de la cámara y su registro particular, que siempre implica un grado de descontrol sobre el material por parte del cineasta, de predominancia de lo que Benjamin llamó un "inconsciente óptico" (2008, p. 39). A diferencia de la sensorialidad del ojo por sí mismo, de lo que sería el consciente óptico, aquél lo contradice en la medida en que lo que encuadra abarca más que lo por él determinado, cuestionando así su pretensión de verdad, su 
racionalización de lo real. Dice Benjamin que nuestro entorno parecía "aprisionarnos sin abrigar esperanzas. Entonces llegó el cine, y con la dinamita de sus décimas de segundo hizo saltar por los aires todo ese mundo carcelario" (2008, p. 38).

La forma del arte cinematográfico es el aporte fundamental, posible gracias a su técnica; esta última conlleva para el artista una "pérdida de poder" (Adorno, 2004, p. 40) particularmente reflejada acá en lo imprevisto del registro fotográfico, que tiene un valor objetivo considerable. Esta forma es el montaje, que implica la presentación fragmentaria de lo registrado, así como la actuación fragmentaria (Benjamin, 2008, p. 31) del actor de cine, respondiendo, como señala von Moltke (2012, p.52) para la aproximación de Kracauer (1960), a la experiencia misma con que dialoga el registro fílmico, a su relación con lo concreto, que es en sí mismo fragmentario - y no unitario, como aparece para la percepción socialmente mediada-. El elemento vital acá es, como argumentan Adorno y Eisler, la sensación, el lograr que los patrones perceptivos "se tambaleen" (2007, p. 42). El montaje produce un "efecto de shock físico" dado por "el cambio de escenarios y de enfoques que penetran a golpes en el espectador" (Benjamin, 2008, p. 42) , y que son tanto más contundentes en cuanto tienen un carácter mimético, una relación real con las dinámicas sociales cosificadas y vueltas contra los individuos. La toma cinematográfica, dice Benjamin (2008, p.42), no puede ser fijada, ya que es a través del shock que el cine, como señalan agudamente Adorno y Eisler, consigue "que la vida empírica, que dice reproducir en virtud de sus inherentes condiciones técnicas, aparezca como algo extraño que permita reconocer la esencia que late bajo la superficie reproducida realísticamente" (2007, p. 42). El montaje como reiteración en cada plano del shock, da cuenta del "contexto social de ofuscación" (Adorno y Horkheimer, 2007, p. 55) que experimentan los individuos como partes intercambiables del engranaje social, es lo que permite vislumbrar la vigencia de un estado de cosas que nos mantiene en un inacabable peligro de muerte. El lenguaje del cine participa, como lo hacía la narración oral premoderna en el Langeweile, de la desestabilización de cualquier pretensión de naturalización del discurso y del orden dado; así como la memoria es apropiada y deformada de narrador en narrador, el cine deforma la percepción socialmente mediada, acusándola de parcial ${ }^{3}$.

"El cine es el único arte que exhibe su materia prima" (Kracauer, 1996, p. 371). Es así que, en el montaje, éste es auténticamente cinemático si busca potenciar esta revelación, no plantear un orden artificial. La intención es, entonces, de potenciación, y no de manipulación del material, y es aquí donde está su autonomía. Benjamin había señalado, en el ensayo de La obra de arte en la época de su reproductibilidad técnica (2008), que, en su uso liberado, el cine, como continuación y potenciación de la fotografía, permitiría una sintonía tal con la época, que daría cuenta, desde su forma, del peligro de muerte correspondiente a sus lógicas y sus ritmos, a la ciudad y al sentido de vida basado en la competencia, de una manera crítica y reveladora: "El cine es la forma artística correspondiente al peligro de muerte acentuado en que los hombres viven hoy en día, y corresponde así a transformaciones de muy hondo calado en el aparato perceptivo" (Benjamin, 2008, p. 42). Esta revelación fragmenta, desde el registro cinematográfico mismo, el estado de armonía mediante el cual, de manera instrumental, las cosas se reducen a su concepto. 
El lenguaje fílmico permite una nueva forma de narración, acorde a las condiciones presentes de abstractividad del lenguaje, de la comunicación como ámbito mercantilizado. La forma mimética de expresión que es el cine, su falta de determinación conceptual, hace posible la presentación, fragmentaria e incompleta, de aquello impresentable conceptualmente: de un estado de cosas hostil. Es así porque es el lenguaje conceptual mismo el que se ha racionalizado para dar pie a un empobrecimiento de las posibilidades humanas de expresión, su reducción al interés privado que media para cada caso, tanto con respecto a los demás hombres como a la naturaleza. En la época de la estandarización de las relaciones sociales para su adecuación al fluctuar del mercado, la forma de arte que se corresponde con estas transformaciones generales de sociabilidad, el cine, hace posible una actualización de la narración oral que, con nuevas características mediadas por su particularidad técnica, se presenta como opuesto y cuestionante de esta reducción en la comunicación humana.

\section{Cine como narración en Medellín}

Lo que argumento es que algunas expresiones cinematográficas en Medellín han logrado, desde su propia construcción del montaje fílmico, esta correspondencia con la época, esta condición crítica de revelación del mundo fáctico en su estado real, esto es, contradictorio. Tres formas de aproximación realista del cine de la ciudad me parecen paradigmáticas: la obra del director Víctor Gaviria desde la década del noventa, el proyecto grupal de Pasolini en Medellín, que tiene un matiz pedagógico central, y el producto etnográfico de Chris Gude, que se lleva al cine en su película Mambo cool (2013). En los tres casos, la memoria de la ciudad es contrastada con el predominante discurso, bastante optimista, del progreso y la innovación. Lo valioso es que dicho contraste es realizado desde el registro mismo de la ciudad, propiciando un choque (shock) al espectador, respecto a su experiencia de ciudad y su percepción del devenir de la misma. El carácter celebratorio de la pujanza regional es confrontado con su inherente contradicción.
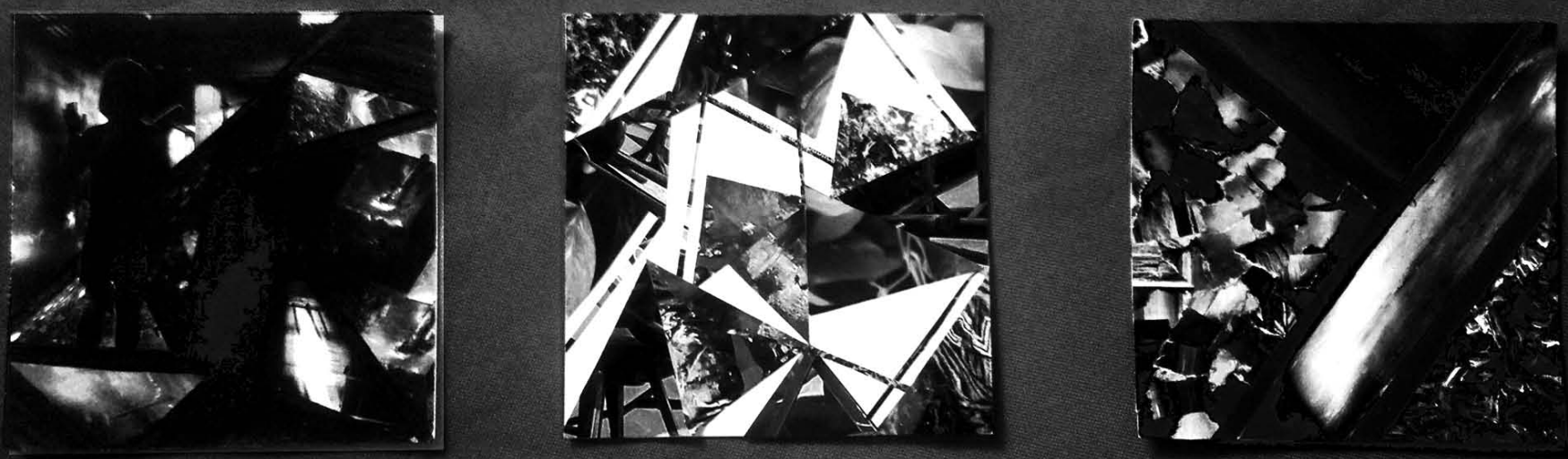
A estos autores, cada uno desde su manera de aproximarse al material, a la realidad registrada por la cámara, se les escapa, se les sale de las manos, lo que queda como obra; el descontrol o "pérdida de poder" (Adorno, 2004, p. 40) que los filósofos críticos de Frankfurt señalan como central en un cine auténtico, adquiere propiedades particulares que permiten comprender de la ciudad y sus situaciones algunas cosas que de otra manera permanecerían ocultas. Lo que se encuentra en este caso particular es que esto sucede por la relación con los actores, que es una interlocución y una construcción dialógica de los contenidos, que determina la forma fílmica y hace colectivo lo narrado, irreducible a una concepción subjetiva. La experiencia fragmentaria y negociada que los actores reproducen en sus actuaciones y relaciones con los entornos que son los suyos propios, complejizan aquello que el registro entrega como un todo, como una unidad, y lo que prima es la contradictoriedad con que, frente a la cámara, los actores son personajes de sí mismos, y más que memorizar un guion o repetir mecánicamente algo prefabricado, recuerdan, hacen memoria de aquello que vivieron o les contaron, o ambos, y que da pie a que ellos sean narradores, desde su corporalidad y su inmersión en la ficción, de la experiencia en su inabarcabilidad. El realismo revelador de Medellín se ha configurado alrededor de estos actores naturales, componiendo una narración desde la cámara, donde todos confluyen desde su expresión particular.

La construcción de memoria y territorio en las películas de estos autores tienen, entonces, un elemento común y axial, que es determinante para las formas finales en que desembocaron: esto es, los actores naturales, y, más concretamente, la interlocución con estos individuos de parte de los directores y equipos de rodaje para plantear, más que un esquema de ficción o teatral, la reconstrucción o revitalización de sus experiencias. Lo que ha sido distintivo en un cine realista de la ciudad, y que ha implicado una representación auténtica de la misma, es decir, sin la imposición de elementos externos, sino desde sí misma, es la valoración e inclusión de individuos narradores, de personas que no van a representar un papel externo a sus condiciones sociales e históricas, sino que van a dar cuenta, en su exposición ante la cámara, de ellos mismos. Ya la ficción es memoria, y los escenarios lugares habitados, socializados y socializantes.

La narración adquiere, así, una forma contemporánea de confrontación ante la reificación de la memoria. El cine permite, bajo unas características específicas, la reapropiación colectiva -y por lo tanto contradictoria, constelativa- de la realidad social, del proceso social y su organización. En el ámbito de la representación se adelantan procesos de reivindicación de la experiencia diversa y compleja, que remiten a la necesidad de un estado de cosas mejor y más justo. 


\section{Realismo y revelación del no futuro:Víctor Gaviria}

Víctor Gaviria es sin duda el cineasta más representativo. El registro de lo concreto en sus obras, de una realidad sin tapujos, pone de manifiesto lo contradictorio de una ciudad que crece pese a quienes la habitan. Él fue quien se dio cuenta, por vez primera para el contexto, de que la realidad urbana de desigualdad y deshumanización sólo podría escapar a su preformación bajo el discurso desarrollista y del progreso pujante en una aprehensión contundente de las experiencias de los sujetos que la padecen, y que no hacen parte de ese discurso por ser ante él contradictorios, contrastantes y desmentidores de su unidad. Los actores naturales, su relación con ellos y su construcción, con ellos, de sus películas, tuvo como resultado una distinción necesaria con respecto al cine anterior y contemporáneo, un cine fragmentario y opaco, visiblemente poco preocupado por el desarrollo de un argumento, y muy centrado en la presentación de un universo.

Su "tríptico de Medellín" (Ruffinelli, 2003, p. 17), como él mismo lo llama, está

compuesto por los tres largometrajes que ha dirigido: Rodrigo D. No Futuro (1990), La Vendedora de Rosas (1998), y Sumas y Restas (2004). El “método dialógico" que utiliza, como él mismo lo llama (comunicación personal, mayo 28 de 2012), es el eje central para la creación artística de sus obras: sus largometrajes son historias construidas a partir de diálogos con los sujetos que experimentaron las realidades que terminaron plasmadas en la pantalla, y fueron también ellos mismos quienes realizaron las actuaciones en los papeles de los personajes que correspondían con su experiencia: ya no hay posibilidad de mofa ni construcción desde el otro, ya no se permite "el subterfugio de la risa" (Suárez, 2009, p. 104), sino que hay una apropiación desde los mismos sujetos, de una manera tal que una traducción estereotipada al estilo comercial de la industria cultural se hace imposible.

Su concepción del cine ya se hace patente con el manifiesto que escribió en colaboración con Luis Alberto Álvarez para la revista Cine en 1982, titulado Las latas en el fondo del río (Ruffinelli, 2003, p. 17; Suárez, 2009, p. 98-99), y donde da cuenta de la importancia del contexto - el lugar de enunciación-, del cine desde la provincia, y que se ve reflejado con el uso de actores naturales y su trabajo y apropiación con su lenguaje (Álvarez y Gaviria, 1982). El registro al uso del lenguaje propio de los actores naturales, en su codificación de la realidad que viven, disfrutan y padecen, es fundamental. Como parte axial de su método de trabajo, "los actores repiten los diálogos que el director les marca, pero a su manera. El léxico y la sintaxis les pertenece; los modismos, también. Las entonaciones les pertenecen, una vez que le son señalados los objetivos de la escena" (Ruffinelli, 2003, p. 26). El cineasta es muy consciente de la importancia de la "jerga" de estos actores, que termina siendo parte de la desvirtuación hacia la sociedad unitaria, de su verdad inamovible que oculta la contradicción interna que permite a unos vivir bien y a otros ser sacrificados; el rechazo a esta objetividad establecida parte de la apropiación por parte de estos 
sujetos marginalizados de su condición como tales; el uso de la "jerga" de los excluidos deviene entonces en crítica hacia el discurso desarrollista institucional. Así se refiere el mismo Gaviria, según cita Ruffinelli:

Todos tenemos jerga; éste no es un privilegio de los más pobres, ni de los jóvenes, ni de los criminales, ni de los niños de la calle. Lo que pasa es que - como sucede con la riqueza - la legitimidad de la cultura no está distribuida simétricamente. Desde que comencé a trabajar con actores naturales comprendí la importancia de esas palabras, del lenguaje que fluye contra la normalidad, contra el lenguaje de los libretistas y el lenguaje literario, o contra la economía de la eficiencia y la comunicación. Entre los niños de la calle, ese lenguaje es una riqueza, una práctica de reconocimiento entre ellos y un espacio de resistencia. (2003, p. 28-29)

A sus películas Gaviria las considera contextuales (comunicación personal, mayo 28 de 2012). El argumento y los personajes no son lo central de sus obras, sino que hacen parte de "expresiones de esos entornos culturales", a los que Gaviria se refiere como "universo". De esta manera, si bien las películas siguen una trama y hay una causalidad entre los hechos que se van sucediendo, lo fundamental de sus imágenes se da en la urdimbre simbólica que recorre cada plano, y que delata costumbres, relaciones, experiencias y formas de significación particulares de la cotidianidad de la ciudad y sus habitantes. En los relatos que reconstruyen el autor y sus interlocutores -los actores naturales- hay una memoria, "un material para poder entender el país, que no estaba precisamente en los escritores, en los libros escritos, sino que estaba en las calles, en las cabezas de la gente" (Gaviria, comunicación personal, mayo 28 de 2012), y que lo remiten a él, como creador de una obra cinematográfica, a pensar un proceso más amplio del que sus mundos hacen parte: para poder entender el conflicto bélico colombiano, desde el magnicidio de Gaitán, la violencia partidista, el bandolerismo, la irrupción de las guerrillas, los grupos armados urbanos, hasta el narcotráfico y el sicariato. Para encontrar todo esto, Gaviria se dio cuenta de que había que "empezar a hablar con la gente”, y esta postura frente a la experiencia propia y de los demás sugiere cercanías de su actitud con el narrador que Walter Benjamin (1991) rescata como quien reconstruye memoria y quien revitaliza el valor de las voces múltiples de un grupo social. En la memoria colectiva que es recuperada por estos sujetos, como Gaviria, la verdad se hace fragmentos, imposible de totalizar, por lo que la realidad se torna en un complejo de contradicciones que sólo es posible buscar reconciliar en su vislumbramiento. La contradicción de la ciudad moderna, centro de civilización, es aquello que sacrifica: la pobreza y el sufrimiento de sus olvidados.

El registro del espacio, de las comunas y los asentamientos que se elevan y que sirven de mirador para toda la ciudad, es también un logro en su obra. Gaviria aborda la ciudad que no fue planeada, sin fachadas limpias y sin presencia institucional. Entre la jerga de los excluidos, sus propias experiencias y los espacios que habitan y significan, se constituye el universo. En este sentido, Rodrigo D. fue, como analiza 


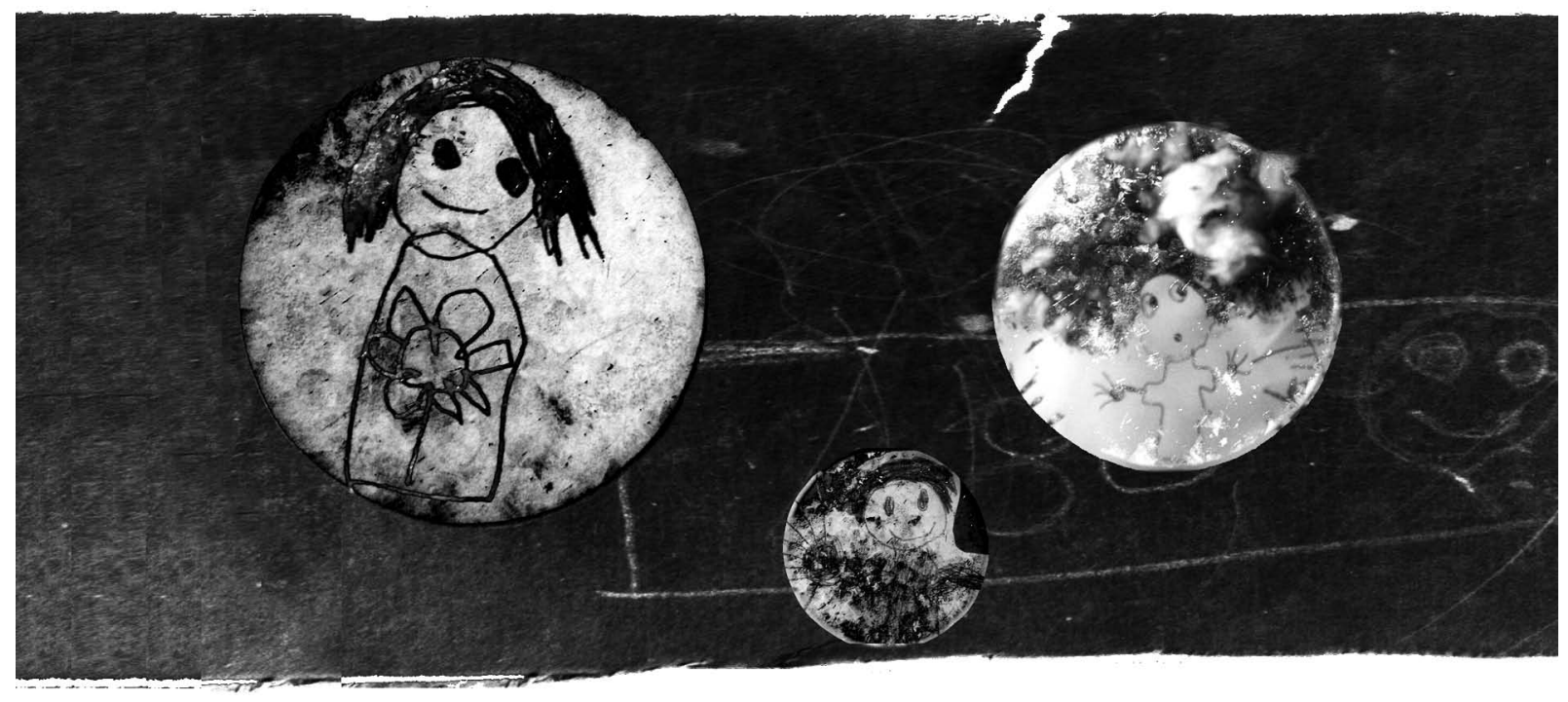

Ruffinelli (2003), el primer intento a fondo de Gaviria para presentarle a la ciudad culta, "al Medellín de clase media (el suyo), la otra ciudad subsumida socialmente (y elevada geográficamente) en las comunas, que esa misma clase media calificaba como "desechable"' (p. 6). En una narrativa coral, se presenta la vida de unos jóvenes sicarios o "pistolocos”: Ramón, “Alacrán”, “Johncito”, Adolfo, "El Burrito”, y particularmente la de Rodrigo, quien está en un estado de profunda depresión desde la muerte de su madre. De fondo a la trama, no sólo como marco sino como razón de ser de la obra, está el universo: las relaciones de estos muchachos entre ellos y con sus familias, con su ciudad y con la institucionalidad - que es nula-, y que en la obra pasa por su rechazo a la escuela y la policía. También se veía, como señala Gaviria, "el proceso del narcotráfico de una manera indirecta" (comunicación personal, mayo 28 de 2012), a partir de la juventud que era contratada por esta mafia. Aquella "habla que estaba excluida" es para Gaviria su más grande hallazgo, y será una de las líneas fundamentales que sostendrá para sus siguientes largos. Según su propia interpretación, esa relación que los sujetos excluidos adquieren con la ilegalidad será dada por la imposibilidad de participar de la ciudad y ser incluidos de otra manera, posición que se interioriza y resignifica para construir, desde el margen, su identidad y participar en la de la ciudad misma:

Hay un momento en que el narcotráfico los acoge, les dan una posibilidad, entonces ellos de alguna manera convierten esa actitud pasiva del azar en una actitud activa del destino. Ya ellos convierten su azar en destino. Entonces ellos ya dicen: "nosotros somos el no futuro de la ciudad", "nosotros vamos a morir muy jóvenes", "nosotros no vamos para ningún lado", "nosotros vamos a matar...” mejor dicho, "nosotros no vamos a... no solamente a esperar que la vida nos desaparezca, sino que nosotros vamos a propiciar esa desaparición, a partir de nosotros ser pistolocos, sicarios, a través de la violencia”. Es un cambio muy grande porque tú te encuentras a estos muchachos al borde de una enorme tristeza, de un sentido trágico de la realidad, que hace que estos muchachos, en un momento determinado, se vuelvan en una voz de conciencia de la ciudad. (Gaviria, en comunicación personal, mayo 28 de 2012) 
En su trabajo, Gaviria, con su metodología de indagación y construcción del relato fílmico, logra el reconocimiento de las relaciones corpóreas y de valores morales que hacen los espacios de ciudad periféricos del no-futuro, aquellos que son constituidos por sus personajes. En sus narraciones, es la violencia aquello que es común a estas diferentes apropiaciones urbanas, que la cámara logra encuadrar gracias a la consciencia de los personajes de su papel activo como narradores de su propia experiencia. El espacio urbano, como pura potencialidad (Delgado, 2002, p. 96) como una producción, el resultado de una actividad humana en él (2002, p. 97) -, es aprehendido por Gaviria en cuanto registra las prácticas de sus sujetos marginales y sus relaciones en ese espacio, es encuadrado y presentado en una circunstancia dada, concreta, que nos permite vislumbrar una de las muchas posibilidades de determinación y significación de sus contenidos; es la captura en la imagen fílmica de "un momento privilegiado de expresión”, como plantea lúcidamente el antropólogo Manuel Delgado (2002, p. 99).

La combinación del elemento de la puesta en escena que provee el cine, y el abordaje dialógico que propone Gaviria con sus interlocutores para la representación de un papel, propician además la posibilidad de análisis de un elemento que Delgado identifica como central en la construcción del espacio urbano: la corporeidad como medio de articulación con este espacio y de relacionamiento con los demás habitantes y transeúntes que lo habitan: "toda práctica social practica el espacio, lo produce, lo organiza, y sólo puede hacerlo a través de esa herramienta con la que sus componentes cuentan y que es el cuerpo" (2002, p. 109). En la obra de Gaviria la auto-representación de los actores naturales, su rol de sí mismos en el argumento fílmico, hacen de la corporeidad en las actuaciones, o más bien, reconstrucciones -de sus recuerdos-, una posibilidad efectiva de conocimiento, una veta muy interesante para la indagación sobre la codificación cultural de las ciudades desde el arte. Como señala el mismo Gaviria en una de sus reflexiones en el documental Cómo poner a actuar pájaros (1998), paralelo al proceso de rodaje de La vendedora de rosas, los actores naturales tienen la capacidad "de verter hacia afuera una experiencia personal", de objetivar en la cámara expresiones de su individualidad que el montaje articula en la narración. La vida real y la vida del personaje no se diferencian claramente. Por el contrario, es su relación de cercanía, incluso de transgresión entre los dos ámbitos, lo que da su particularidad a esta forma de realismo y de narración.

El resultado es la posible conceptualización que realiza de un estado de no futuro que describe la condición de la ciudad. El no futuro es puesto en evidencia desde estos personajes a los que Gaviria se pone en la tarea de dar voz, porque los niños sicarios de Rodrigo D. o las niñas de LaVendedora de Rosas, como plantea, ni siquiera son explotados dentro del sistema de producción, sino que son totalmente excluidos: "eran personas que estaban por fuera, incluso, de cualquier institucionalización a través de una fábrica, o de una relación con los patrones que los convertía a ellos en obreros, en trabajadores" (comunicación personal, mayo 28 de 2012). Como fatalidad de este no futuro, muchos de sus actores naturales murieron en esa vida violenta que llevaron, y que no fue comprendida como prolongación de la ciudad culta; su expresividad y 
apropiación de la realidad ha sido lo no-culto, lo negado con fastidio y recelo, como si la posición de privilegio de algunos no estuviera directamente condicionada por la posición de inferioridad del resto:

Hay un poder enorme en la habilidad para comunicarse con otros sin ser comprendido por todos, como lo saben, entre otros, los abogados y los críticos literarios. El lenguaje de la calle es un lenguaje de guerra que designa muy bien ese mundo y en el que se juega la obstinación de ciertas identidades. Algunos espectadores — claro- se cansan de oír las palabras gonorrea, hijueputa, faltón, malparido. Ese problema, el de la traición a la inteligibilidad, es en todo caso un problema más fácil que el que tiene aquel que sufre la traición diaria de la vida. Es más sencillo no ver una película o irritarse por la palabra gonorrea que admitir que para muchos el mundo es literalmente una gonorrea (Gaviria, 2002, en Ruffinelli, 2003, p. 29).

\section{Cine y lúdica: Pasolini en Medellín}

Pasolini en Medellín, como grupo interdisciplinar de creadores audiovisuales de la ciudad, de alguna manera conservan y dialogan con esta noción del universo y del realismo dialógico para registrar la ciudad y la región en algunos de sus trabajos. Éstos tienen un valor pedagógico y de apropiación de la imagen en movimiento, ya que la cámara se desliga acá, mucho más, de un individuo creador, y es ojo directo del actor, de él y no frente a él. Los grupos sociales que pertenecen a los contextos donde llega la corporación participan de una manera directa de lo que se está queriendo decir, se da una apropiación de la cámara y su potencial para la narración, ellos participan del proceso total de su película. Hay un uso lúdico del lenguaje fílmico, cuyo efecto es la relación de la representación fotográfica con la praxis social, una articulación donde el cine transgrede su uso tradicional en la división entre creador y espectador, y cumple, a su manera, el proyecto benjaminiano donde es una cuestión ética y epistemológica, del derecho de filmar y ser filmado (Benjamin, 2008, p. 33) con que la nueva forma de arte de la modernidad del siglo xx se sumerge en la cotidianidad.

Su trabajo, no sólo en producción de imágenes en movimiento sino también pedagógicas (talleres barriales y universitarios), ha sido amplio si bien intermitente. Un ejemplo importante es el corto titulado El juego de la vida (2008) que, aunque no es reciente, reúne una serie de elementos característicos de manera muy lograda. Realizado con el apoyo de la Universidad de Antioquia y el Instituto de Estudios Regionales INER, convoca a niños y jóvenes habitantes del Barrio Popular No. 1 de Medellín para representar una situación de violencia en el sector, donde los actores son los habitantes y el entorno, así mismo, el suyo propio. En la obra se puede apreciar, por algunas tomas posteriores al desenlace, el trabajo con la comunidad, de sensibilización y apropiación de la representación en la cámara, a partir de la cual los niños jugarían y serían testigos, en el desarrollo de la obra, de un evento donde se da una persecución y los amenazarían algunos jóvenes pertenecientes de un grupo armado. 
El trabajo de Pasolini en Medellín no se reduce al ámbito urbano más inmediato, sino que su proyección aspira a abarcar el Departamento y sus coyunturas particulares. Rodando por Antioquia, de 2013, es un proyecto de una serie de trece cortometrajes del grupo en diferentes municipios afectados gravemente por el conflicto armado, y donde el propósito está en la construcción colectiva de historias, escritas y realizadas por jóvenes, sus familias y docentes en cada contexto concreto. El corto Memorias de escuela, realizado en San Carlos, es, por ejemplo, una creación colectiva de estudiantes, familiares y docentes de la Institución Educativa Rural Palmichal, la Institución Educativa Joaquín Cárdenas Gómez, la corporación Pasolini en Medellín y el Programa Gestión Ciudadana de la Fundación Smurfit Cartón de Colombia. La mirada de los niños sobre la guerra, la decisión de ir a buscar a quien se llevaron los armados, tan irrealizable en el contexto real como necesaria y muestra de una impotencia colectiva, contrasta lo que la narración continúa entre un marco formal de justicia social que es enseñado y un entorno que lo niega en distintos hechos contundentes: desplazamiento, minas y secuestro. La escuela se va quedando vacía y los pupitres dan cuenta de la imposibilidad de expresión del sufrimiento, que en la obra se plasma sin determinarlo ni agotarlo en la representación. Que en la imagen los niños se apropien del territorio que ha dejado de connotar habitabilidad y sociabilidad para ellos contradice el estado de cosas dado en la claridad de que la ficción sólo presenta lo sublimado, y no la consumación del deseo.

Tanto en El juego de la vida como en Memorias de escuela, Pasolini en Medellín convoca a la narración colectiva de las experiencias particulares que constituyen un contexto. No hay un interés informativo en los términos que describí más arriba, como oposición a un despliegue narrativo, donde se apela al dato suelto y la reducción de cada conflicto particular a un marco común de violencia. Cada caso es una narración porque no apela a estandarizaciones ni a esquemas de desarrollo, sino que parte de las experiencias mismas de las personas, por lo que estos productos son enfáticos en su condición concreta, en su particularidad. En otras palabras, su valor es estrictamente cualitativo, y no cuantificable como información, como abstracción.

\section{Un gringo en Medellín: Chris Gude}

El tercer caso que quería proponer es el de Chris Gude, que en su película Mambo Cool recurre a la etnografía, como antropólogo que es, para aproximarse a quienes luego, sin todavía saberlo, protagonizarían su película. Como producto colectivo, indivisible a una sola voz, o a una diferenciación entre voces, la obra pone en relación a los individuos con los espacios que les han dado su condición. Tras un proceso de cuatro años (Arenas, 2015) de relación con los sujetos que se representarían a sí mismos en la obra, la película se propone seguir un desarrollo rítmico, a partir de la música que aportan los diferentes contextos y personajes, desde cumbia y boleros hasta el mambo, que connotan los sucesos fragmentarios que componen este universo coral. 
Como sucediera en diversos medios con la obra de Gaviria, el trabajo de Gude ha resultado problemático para una representación de la ciudad afirmativa y unidimensional, al presentar un ámbito de drogadicción y prostitución. Al respecto, el periodista Sergio Esteban Vélez (2013) comenta, en su artículo para el periódico El Mundo titulado “¿Un gringo reforzando prejuicios sobre Colombia?”:

El enfoque de la cinta no tendría relación alguna con los paisajes de nuestra ciudad ni con sus avances arquitectónicos y cívicos ni con la belleza de sus mujeres... ni siquiera con los contrastes de clases sociales. Solo hubo espacio para la indigencia, la drogadicción, la prostitución y la criminalidad, en estancias cerradas que impiden contemplar el cielo y el paisaje medellinenses. De todo lo que Gude vio en Colombia, esto fue lo que más le llamó la atención y lo que consideró pertinente mostrar en el exterior. (Vélez, 2013)

Este papel claro que se le impone al cine, de dar cuenta de un estado de armonía y atravesado por una condición de progreso, que se aferra a una mediación ajena a lo real concreto, es sacudido en el registro sin tapujos, descontrolado, que parte de la realidad misma para la composición en el montaje cinematográfico. Gude, lejos de teatralizar su puesta en escena, prolonga la interioridad de los drogadictos y enfermos de la ciudad en sus rostros, sus actos y su apropiación de los espacios que habitan y transitan: "La historia siempre fue dictada por el lugar y los personajes. A eso es a lo que queríamos ser fieles, no a un guion", dice en la entrevista mencionada para el periódico El Mundo.

\section{A modo de conclusión}

El cine realista de Medellín no sólo es coral en cuanto el universo está compuesto por diversos personajes no jerarquizados, sino que su coralidad está también en la construcción misma de la obra, en aquello que verbal, corporal o espacialmente se expresa, y que en cada momento exige del director o creador ser tanto narrador como escucha. La "autenticidad" o "realidad de las historias" a que apela Gaviria, según afirma en Cómo poner a actuar pájaros, está en esa desintegración de las posiciones de autor y actores: "los niños son los autores del guion y los autores de la película", así como en los trabajos mencionados de Pasolini en Medellín, los niños y jóvenes recrean ellos mismos un suceso y una situación profunda de su cotidianidad, y los drogadictos de Mambo cool aportan su intimidad, su quehacer y sus cuerpos. La preparación de una pipa en esta última obra, la habilidad de esas manos en ese momento anónimas, es realmente su preparación; ésta será utilizada sin duda, así como los "pistolocos" de Rodrigo D. manejan su motocicleta en función de matar o robar como muchas veces antes, sin apelar a nada desconocido. La torpeza en la actuación, que es una resistencia a la estandarización, es precisamente porque estos no-actores o actores naturales no están actuando, no están realizando "ejecuciones de una prueba” (Benjamin, 2008, p. 27) ante la cámara, de memorización de unas líneas e indicaciones técnicas de corporalidad, sino que ellos están recordando. El valor de este lenguaje fílmico es su 
actualización de la narración, si bien su proporción es mínima y en muchos casos su divulgación también. Lo que hay es una nueva forma de comunicabilidad de la experiencia, en un estado de cosas social donde, precisamente, lo que Benjamin señala es una pérdida de esta facultad.

El contexto hace, además, que la indagación artística tenga una pertinencia impensada: la narración se renueva en el cine realista de Medellín como una respuesta que pone en evidencia el malestar ante el optimismo oficial y cotidiano. El cine acusa un estado de cosas falso, esto es, una mejora en las condiciones de vida desde soluciones imbricadas en intereses privados en la ciudad, a partir de la reivindicación de la multiplicidad de voces que constituyen su memoria. Desde el registro del espacio hasta el planteamiento de situaciones específicas (lo sincrónico y lo diacrónico), y atravesado todo por el interés en el no-actor, se manifiesta una necesidad expresiva ante la experiencia contradictoria de la ciudad. No es fortuito el malestar que estas propuestas estéticas han despertado en diversos grupos ciudadanos y en la opinión pública; como señalo acá para el caso de Mambo Cool, es precisamente un anhelo de verdad que, en modo negativo, y meramente desde el arte, presenta y ordena el mundo de manera que, por el discurso ideologizado imperante que es incluso política oficial, no podría aparecer de otra forma. El montaje, como forma de narración del capitalismo tardío, puede tomar lo mejor del avance técnico y darle un uso reivindicador para la representación del anhelo social por el derecho a la ciudad.

\section{Notas}

${ }^{1}$ Este artículo es un derivado del proyecto de investigación titulado "Cine y nación: negociación, construcción y representación identitaria en Colombia”, que realizó el autor entre 2012 y 2013 en el Grupo de Investigación y Gestión sobre Patrimonio GIGP, de la Facultad de Ciencias Sociales y Humanas de la Universidad de Antioquia. Una versión más corta del texto fue presentada como ponencia en el Congreso Nacional Diálogo de Saberes en Comunicación en la Universidad de Medellín en 2015.

${ }^{2}$ Antropólogo, Magíster en Filosofía, Universidad de Antioquia.

${ }^{3}$ Es por eso que los dos tipos arcaicos que Benjamin identifica como narradores son el viajero (el marino mercante), y el sedentario (el campesino) (Benjamin, 1991, 113), que tanto en su intenso movimiento y experiencia de lo otro, o su insistencia en la particularidad de su entorno, convocan y en ellos confluyen experiencias que los trascienden como individuos, que, fundamentalmente, no están aislados.

${ }^{4}$ Para una profundización en la problematización de la Escuela de Frankfurt de la razón instrumental contemporánea, se recomienda revisar Crítica de la razón instrumental, de Max Horkheimer (2002), y la Dialéctica de la Ilustración, de Th. W. Adorno y Max Horkheimer (2007).

${ }^{5}$ El problema no es el carácter parcial de la percepción humana socialmente mediada por el contexto específico, sino su pretensión de totalidad, de unidimensionalización de la realidad, siguiendo a Marcuse (1985). 


\section{Referencias}

Adorno, T. y Eisler, H.. (2007). Composición para el cine. El fiel correpetidor. Obra Completa, 15. Madrid: Akal.

Adorno, T. y Horkheimer, M. (2007). Dialéctica de la Ilustración. Obra Completa, 3. Madrid: Akal.

Adorno, T. (2004). Teoría Estética. Obra Completa 7. Madrid: Akal.

Álvarez, L. A. y Gaviria, V. (1982). Las latas en el fondo del río. Recuperado el 20 de septiembre de 2012, del sitio web Cinéfagos: http://www.cinefagos.net/index.php?option=com_ content\&view $=$ article $\&$ id $=423$ :el-cine-colombiano-visto-desde-la-provincia\&catid $=30:$ documentos\&Itemid $=60$

Arenas, A. (2015). Chris Gude: "La estructura de Mambo Cool siempre buscaba un ritmo más musical y no un ritmo narrativo”. Recuperado el 11 de abril de 2015, del sitio web Revista Magnolia: http: / / revistamagnolia.es/2015/02/chris-gude-la-estructura-de-mambo-cool-siempre-era-un-ritmomas-musical-y-no-un-ritmo-narrativo /

Benjamin, W. (1982). Pequeña historia de la fotografía. En: Discursos Interrumpidos I. Madrid: Taurus. Pp. 61-85.

Benjamin, W. (1991). El Narrador. En: Iluminaciones IV. Para una crítica de la violencia y otros ensayos. Madrid: Taurus. Pp. 111- 134.

Benjamin, W. (2008). La obra de arte en la época de su reproductibilidad técnica. Primera Redacción. En: Obras, Libro I/ Volumen 2. Madrid: Abada Editores. Pp. 7-47.

Delgado R., M. (2002). Disoluciones urbanas. Medellín: Editorial Universidad de Antioquia.

Horkheimer, M. (2002). Crítica de la razón instrumental. Madrid: Trotta.

Kracauer, S. (1995). De Caligari a Hitler. Una historia psicológica del cine alemán. Barcelona: Paidós.

Kracauer, S. (1996). Teoría del cine. Barcelona: Paidós.

Marcuse, H. (1985). El hombre unidimensional. Barcelona: Editorial Planeta - De Agostini.

Moltke, J.. (2012). Manhattan Crossroads. Theory of Film between the Frankfurt School and the New York Intellectuals. En: Culture in the Anteroom. The Legacies of Siegfried Kracauer. Chicago: The University of Michigan Press. Pp. 42-60.

Ruffinelli, J. (2003). Víctor Gaviria. Cuadernos de cine colombiano, Cinemateca Distrital, No. 3, 4-55.

Suárez, J. (2009). Cinembargo Colombia: ensayos críticos sobre cine y cultura. Bogotá: Editorial Universidad del Valle.

Vélez, S. E. (2013). ¿Un gringo reforzando prejuicios sobre Colombia? Recuperado el 11 de abril de 2015, del sitio web El Mundo:http:/ / elmundo.com/portal/cultura/cultural/un_gringo_reforzando_ prejuicios_sobre_colombia.php\#.VSnzqJPeMhR

\section{Filmografía}

Cómo poner a actuar pájaros, 1998. Dir: Erwin Göggel, Sergio Navarro y Víctor Gaviria, Prod: Producciones Erwin Göggel. Colombia, 90 mins.

El juego de la vida, 2008. Dir:Yosmán Puerta, Prod: Elsy Galeano, Yosmán Puerta, Amada Pardo y Yenny Martínez. Colombia, 8 mins.

La vendedora de rosas, 1998. Dir: Víctor Gaviria, Prod: Producciones Filmamento, Producciones Erwin Göggel, Colombia, 115 mins.

Mambo Cool, 2013. Dir: Chris Gude, Prod: Juan Pablo Pardo. Colombia, Estados Unidos, 62 mins.

Memorias de escuela, 2013. Dir: Elkin García, Prod: Carlos Galán, Pasolini en Medellín. Colombia, 11 mins.

Rodrigo D. No Futuro, 1990. Dir: Víctor Gaviria, Prod: Compañía de Fomento Cinematográfico - Focine, Producciones Tiempos Modernos Ltda., Fotoclub 76, Colombia, 91 mins.

Sumas y restas, 2004. Dir: Víctor Gaviria, Prod: Burn Pictures, Latin Cinema Group, La Ducha Fría Producciones, Latino Films, A.T.P.P. Producciones. Colombia, 105 mins. 